\title{
Current control of grid connected three phase current source inverter based on medium power renewable energy system
}

\author{
S.A.Azmi ${ }^{*}$, G.P.Adam ${ }^{2}$, S.R.A.Rahim ${ }^{1}$ and B.W.Williams ${ }^{2}$ \\ Faculty of Electrical Engineering Technology, Universiti Malaysia Perlis, Malaysia ${ }^{1}$ \\ Department of Electronic and Electrical Engineering, University of Strathclyde, Glasgow, United Kingdom²
}

Received: 14-October-2020; Revised: 16-January-2021; Accepted: 19-January-2021

(C)2021 S.A.Azmi et al. This is an open access article distributed under the Creative Commons Attribution (CC BY) License, which permits unrestricted use, distribution, and reproduction in any medium, provided the original work is properly cited.

\begin{abstract}
Current source inverter (CSI) features simple converter structure and inherent voltage boost capability. In addition, it provides low instantaneous rate of voltage change with respect to time in comparison to voltage source inverter (VSI) and multilevel inverter (MLI). Nonetheless, CSI does not outshine as grid interfacing unit in photovoltaic (PV) generation system. This is because of requirement of large sizing of dc-link inductor and sluggish performance during light load condition. Contemplating both advantages and disadvantages of CSI, this work is aimed to investigate and analyze the superiority of CSI in PV system. The proposed system employs direct regular-sampled pulse width modulation (DRSPWM) as modulator and multi-loop proportional-integral (PI) in synchronous frame as the controller. The gridconnected CSI system is further evaluated along with photovoltaic maximum power point tracking (PV-MPPT) control. Simulation verification highlighted that the option of using CSI as medium power PV grid integration unit in exchanging active-reactive power with grid network is very satisfactory. In addition, balanced sinusoidal output currents with acceptable harmonic limit are successfully achieved; like other topologies in PV grid integration. The proposed CSI system is proved to be able to track the references in event of varying input condition from PV array. The theoretical equations and modeling are described, and the simulation are conducted in MATLAB / Simulink platform.
\end{abstract}

\section{Keywords}

Current source inverter, PI control, Current control loop, Photovoltaic system, Grid connected converter.

\section{Introduction}

A dc-ac converter consists combination of active switches connected with passive components which acted as interfacing unit between the dc input source and ac loads or grid ac network. Looking at the type of signal at the dc input side, the inverter can be categorized as voltage source inverter (VSI) and current source inverter (CSI). Single-phase, threephase and multilevel switching arrangements are suited for those inverter topologies, depending on the voltage and rated power requirements of the dedicated application.

For grid connected application, the inverter plays an important role in the integration of distribution generation onto ac grids. Such integration is governed by strict grid codes, which include the control of active and reactive power and permissible levels of harmonics.

*Author for correspondence

34
From perspective view of photovoltaic systems and wind turbines in multimegawatt ranges, current source inverter (CSI) topology seems a better preference as compared to its competitor, VSI and MLI [1-6].

This is because CSI provides a simpler topology, able to perform satisfactory in grid and island mode, provides balanced sinusoidal output current and able to protect naturally against dc-side short-circuit faults. Although, as yet, the CSI does not play a major role as a grid interfacing unit in distributed generation systems. It is only a proven approach in ac drives systems with high rated power and medium voltage ranging between $2.3 \mathrm{kV}$ to $13.8 \mathrm{kV}[3,4]$. This is because of the drawback of CSI which requires large sizing of dc-link inductor in order to keep the dc-link current almost constant, stability problem and sluggish performance especially in light load condition.

Despite the disadvantages suffered by CSI, the work is intended to highlight the possibility of using CSI as 
the interfacing unit where the advantages offered able to weight-scale its potential. A single-stage medium power grid connected photovoltaic system based on a two-level three-phase CSI is proposed in this work.

This work is intended:

- to investigate the possibility of using CSI as an alternative topology used for grid interfacing unit.

- to propose a CSI control system consists of direct regular-sampled pulse width modulation (DRSPWM) and multi-loop proportional-integral for the power exchanges with the grid and;

- to evaluate the performance of grid connected three-phase CSI using the proposed control system under varying operational parameter.

The proposed CSI control system uses DRSPWM technique as modulator and multi-loop proportionalintegral (PI) [7] to regulate the active and reactive power exchanges with the ac grid under various operating conditions. The theoretical equations and modeling of the proposed control system is explained in subsequent section. The performance of the inverter system under varying operational conditions is verified through MATLAB/Simulink platform. The contents of this paper are organized as follows: Section 2 describes the theoretical background of PI control in synchronous frame which consists of power and current control loops in photovoltaic system. Section 3 analyzes and verify the performance of the proposed multi-loop control CSI with exchanges active and reactive medium power to the grid. Finally, the conclusion in Section 4 concludes the significant results and findings of the research work.

\section{Literature review: three-phase current source inverter system}

In photovoltaic system, the CSI has been a promising topology in boosting the efficiency of maximum power point tracking (MPPT) since it can reduce the number of PV series connected to each string [5-9]. This significantly reduces the effect of partial shading and improving the system efficiency by adopting only single stage conversion, thanks to inherent voltage boost capability of the CSI $[6,10,11]$. The single-phase CSI for photovoltaic grid integration is proposed in [12-15] which introduce various transformer less topologies to minimize the commonmode current that arises through the stray capacitance between the PV array and ground. Also, the proposed single-phase topologies need to cater for even harmonics on the dc side [13]. Novel single-phase with six-switches arrangement introduced in [15] 35 able to eliminate high-frequency common-mode voltage, results in lower total harmonic distortion (THD). These need to be eliminated since they affect MPPT in term power tracking and may reduce lifetime of PV inverter [12].

Several applications of three-phase CSI in photovoltaic systems are proposed in $[10,14,16]$. Analysis and modelling of a grid connected CSI, using PI control in the synchronous frame and carrier-based SPWM, are presented in [10]. However, the controller consists only of the current control loop, which affects the system reliability. In [14], the proposed system consists of only one control loop for maximum power point tracking, and is claimed to generate an ac output current with THD of $4.5 \%$. A modified carrier-based SPWM technique is proposed which adds a short-circuit pulse to the conventional SPWM to prevent an open-circuit CSI at any instant, and which is useful in adjustment of the PV-array voltage [14]. Although a simple MPPT control structure is introduced, limited experimental results and information on the control system are presented [14]. Meanwhile in [16, 17], reverse-blocking IGBTs with Phasor Pulse Width Modulation are used in three-phase CSI which enable higher system efficiency, higher boost ratio and elimination of stepup stages by means of boost converter or step up transformer. This work is verified using hardware prototype of $2 \mathrm{~kW}, 208 \mathrm{Vl}-\mathrm{I}$, rms and varying dc input voltage between $60 \mathrm{~V}$ to $120 \mathrm{Vdc}$.

Topology of CSI is further improved in $[18,19]$ by introducing series-connected CSIs with fewer number of switches which permit lower switching losses and reduced sizing of passive components in the circuit. With the use of very low switching frequency, which is $60 \mathrm{~Hz}$ and higher dc current utilization, this topology features a promising candidate for highvoltage application. Looking at the other application, current source inverter in [19] is applied effectively in motor drives application. An improvement of current control scheme is introduced to eliminate the need for front-end stage which taking advantage of higher efficiency and simpler operation. More interesting research works are crucial to support this promising topology approach in variety of application.

Taking a step back for clarification on the topology of CSI, Figure 1 illustrates the basic schematic diagram of six self-commutated unidirectional switches with series diodes three-phase two-level CSI connecting to the ac grid. This schematic is powered 
by dc-voltage source in series with dc-link inductor. The ac power-filters which consists of combination of capacitors and inductors are functioned in minimizing the high frequency harmonic components linked to the switching frequency of the modulator [20]. The performance of grid connected current source inverter-based PV system is investigated in this work and it is controlled by proportional-integral control in synchronous frame and DRSPWM as modulator. The detail of direct-regular sampled PWM is extensively discussed in [7, 8] thus will not be covered in this work. The presented control variables are exploited for regulation of active and reactive powers exchanges with grid network.

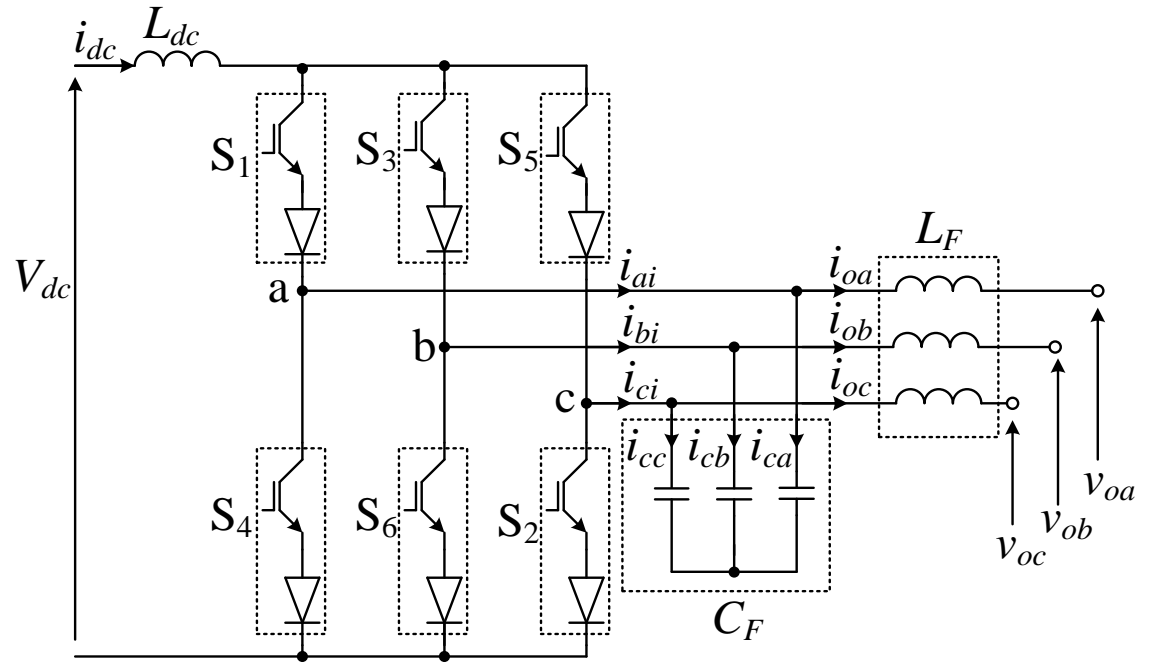

Figure 1 Schematic diagram of three-phase CSI circuit

Based on Figure 1, the dynamic equations (1) to (4) describe d-q axes of CSI circuit. Grid phase voltage, vo is associated to d-axis as follows:

$$
\begin{aligned}
\frac{d i_{o d}}{d t} & =-\frac{R_{F}}{L_{F}} i_{o d}+\frac{\left(v_{c d}-v_{o d}+\omega L_{F} i_{o q}\right)}{L_{F}} \\
\frac{d i_{o q}}{d t} & =-\frac{R_{F}}{L_{F}} i_{o q}+\frac{\left(v_{c q}-v_{o q}-\omega L_{F} i_{o d}\right)}{L_{F}} \\
\frac{d v_{c d}}{d t} & =\frac{i_{i d}-i_{o d}+\omega C_{F} v_{c q}}{C_{F}} \\
\frac{d v_{c q}}{d t} & =\frac{i_{i q}-i_{o q}-\omega C_{F} v_{c d}}{C_{F}}
\end{aligned}
$$

Equation (1) and (2) represent the output current in dq-term considering grid voltages and filtered capacitor voltages at ac-side. Equation (3) and (4) describe the filtered capacitor voltage with reference to pre-filtered currents, ac output currents and grid voltages. The terms $v_{o d}$ and $v_{o q}$ represent the $d$ - $q$ term of the grid phase voltage. The filtered capacitor voltages are represented by $v_{c d}$ and $v_{c q} i_{o d}, i_{o q}, i_{i d}$ and $i_{i q}$ represent the ac output and pre-filtered currents in dq-term. The filter resistance, inductance and capacitance are represented by $R_{F}, L_{F}$ and $C_{F}$ accordingly.

The power control loop controls the average power flow which ultimately produces high quality sinusoidal output currents. Grid voltage is assumed to be fixed, thus the active and reactive power of the inverter exchanges in reference to the grid are regulated by regulating the d-q quantities of output current directly. The reference current, $i_{o(d q)}^{*}$ that needs to be injected into the grid is expressed in (5).

$\left[\begin{array}{l}i_{o d}^{*} \\ i_{o q}^{*}\end{array}\right]=\frac{2}{3} \frac{1}{v_{o d}^{2}+v_{o q}^{2}}\left[\begin{array}{cc}v_{o d} & v_{o q} \\ v_{o q} & -v_{o d}\end{array}\right]\left[\begin{array}{l}P^{*} \\ Q^{*}\end{array}\right]$

\section{Methodology: proposed current control loop for CSI system}

Figure 2 presents the current control system of a grid-connected CSI which consists of a phase locked loop, outer current regulator, inner voltage regulator, and the direct-regular sampled SPWM. The presented control structure uses several feedback loops with PI controllers in the synchronous frame, and feedforward control to enhance the system's ability to reject disturbances. The direct-regular sampled PWM 
is used to generate the CSI switch gating signals. With this arrangement, system stability, dynamic response and response time are improved, with output harmonic elimination. To control the power flow, Io is the outer control variable while for the inner loop, capacitor voltage, $\mathrm{Vc}$ enhances controller bandwidth [20].

The current control in CSI system shows in Figure 2 comprise of two cascaded control loop; the outer loop adjusts the magnitude and phase of pre-filtered capacitor voltages corresponding to grid voltage. This is based on equation (5) which is designed based on equations (1) and (2). Following, the outer current control autonomously provides a set-point to the inner control loop which involving feedback from filter capacitor voltages. This is based on equations (3) and (4).

To assist the current regulator design, let $w_{d}=v_{c d}^{*}-v_{d}+\omega L_{F} i_{o q}$ and $\quad w_{q}=v_{c q}^{*}-v_{q}-\omega L_{F} i_{o d}$, where the new variables $w_{d}$ and $w_{q}$ are attained from PI controller as in (6) and (7):

$$
\begin{aligned}
& w_{d}=k_{P 1}\left(i_{o d}^{*}-i_{o d}\right)+k_{I 1} \int\left(i_{o d}^{*}-i_{o d}\right) d t \\
& w_{q}=k_{P 1}\left(i_{o q}^{*}-i_{o q}\right)+k_{I 1} \int\left(i_{o q}^{*}-i_{o q}\right) d t
\end{aligned}
$$

where $k_{P I}$ and $k_{I I}$ are proportional and integral gains of the current regulators in the $d$ and $q$ terms.
The integral parts of (6) and (7) are replaced with $z_{d}$ and $z_{q}$, and substituting the resultant expressions in (1) and (2), gives:

$$
\begin{aligned}
\frac{d i_{o d}}{d t} & =-\frac{\left(R_{F}+k_{P 1}\right)}{L_{F}} i_{o d}+\frac{z_{d}}{L_{F}}+\frac{k_{P 1}}{L_{F}} i_{o d}^{*} \\
\frac{d i_{o q}}{d t} & =-\frac{\left(R_{F}+k_{P 1}\right)}{L_{F}} i_{o q}+\frac{z_{q}}{L_{F}}+\frac{k_{P 1}}{L_{F}} i_{o q}^{*} \\
\frac{d z_{d}}{d t} & =k_{I 1}\left(i_{o d}^{*}-i_{o d}\right) \\
\frac{d z_{q}}{d t} & =k_{I 1}\left(i_{o q}^{*}-i_{o q}\right)
\end{aligned}
$$

The differential equations (8) to (11) are rearranged in a form of state space formulation, $x^{\prime}(t)=A x(t)+B u(t)$ as:

$\frac{d}{d t}\left[\begin{array}{c}i_{o d} \\ z_{d} \\ i_{o q} \\ z_{q}\end{array}\right]=\left[\begin{array}{cccc}-\frac{\left(R_{F}+k_{P 1}\right)}{L_{F}} & \frac{1}{L_{F}} & 0 & 0 \\ -k_{I 1} & 0 & 0 & 0 \\ 0 & 0 & -\frac{\left(R_{F}+k_{P 1}\right)}{L_{F}} & \frac{1}{L_{F}} \\ 0 & 0 & -k_{I 1} & 0\end{array}\right]\left[\begin{array}{c}i_{o d} \\ z_{d} \\ i_{o q} \\ z_{q}\end{array}\right]+\left[\begin{array}{cc}\frac{k_{P 1}}{L_{F}} & 0 \\ k_{l 1} & 0 \\ 0 & \frac{k_{P 1}}{L_{F}} \\ 0 & k_{I 1}\end{array}\right]\left[\begin{array}{l}i_{o d}^{*} \\ i_{o q}^{*}\end{array}\right]$

Equation (12) shows the states that have d-channels can be controlled independently without the influence of q-channels. Thus, the decoupled control of reactive and active can be successfully achieved.
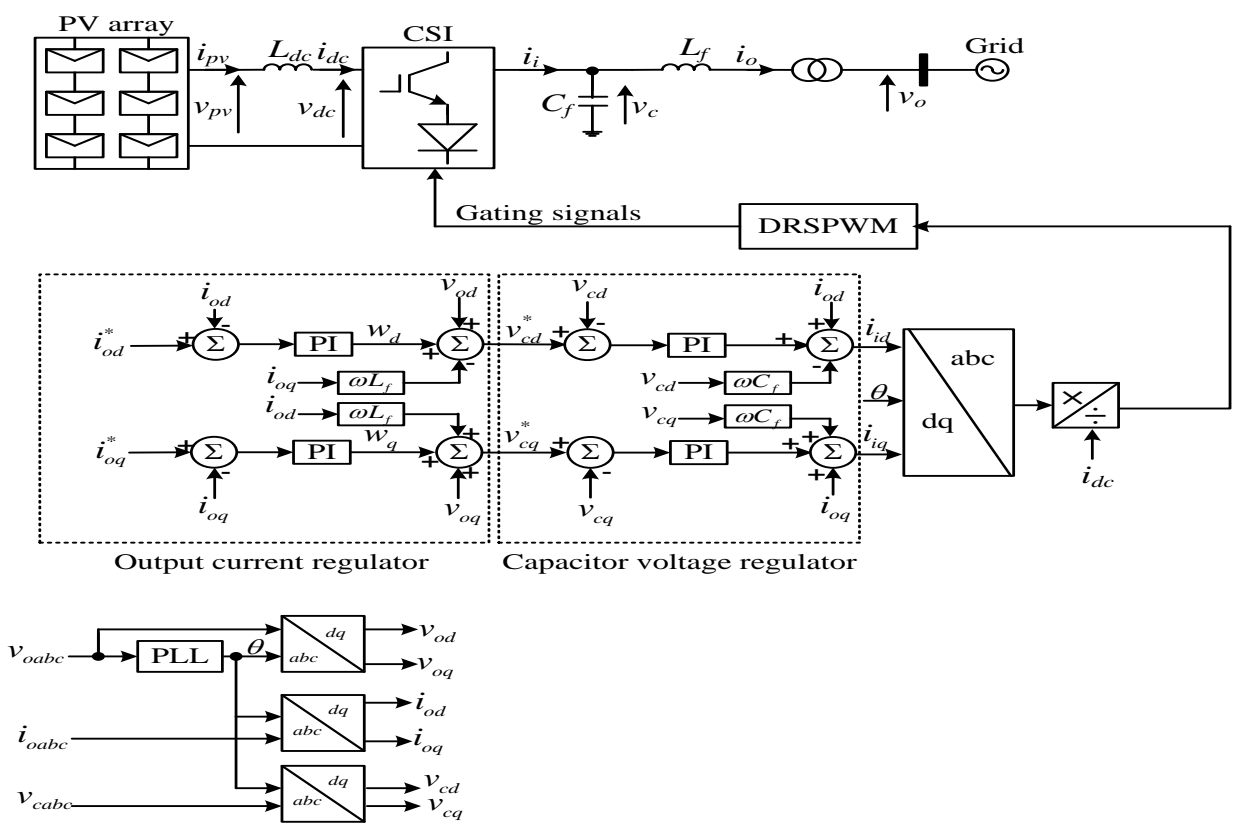

Figure 2 Block diagram of current control arrangement of CSI as grid interfacing unit 


\section{S.A.Azmi et al.}

\subsection{Current control loop of CSI in photovoltaic system}

In photovoltaic system, CSI is used to serve both functions which are to track the maximum power point tracking and interfacing unit between PV system and the ac grid system. Similar control system in Figure 2 is implemented in Figure 3 with exception dc-link voltage regulator for maximum power point tracking. The inverter dc-link voltage is adjusted as accordance to the weather changes. This is to ensure the maximum power extracted at all times. This has been simulated with the aid of the lookup table that contains a pre-defined PV I-V characteristic. Weather condition variations are simulated by variable current from the PV arrays, which is assumed as the input signal to the lookup table.

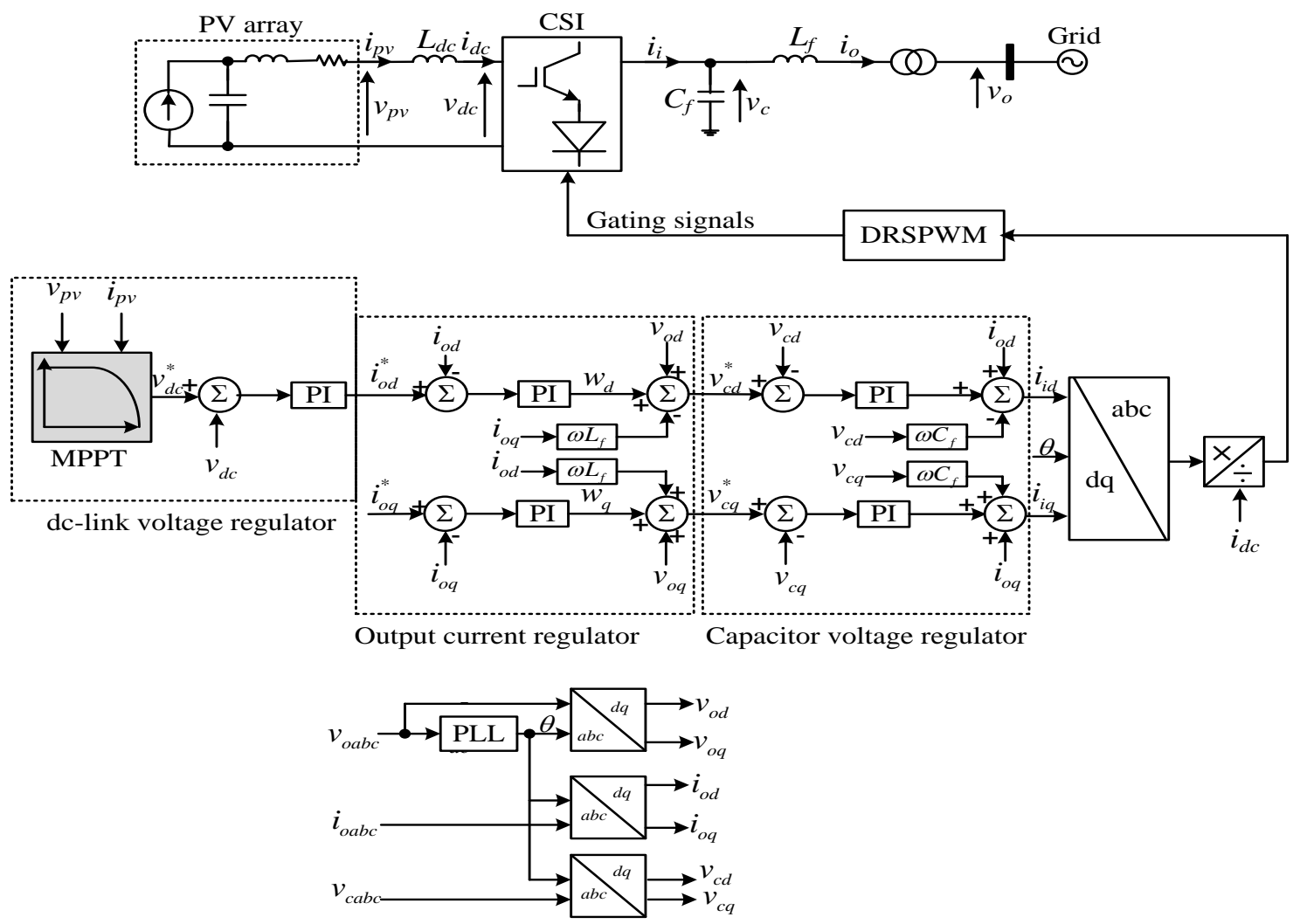

Figure 3 Test system of a grid-connected CSI for photovoltaic application

\section{Result and discussion: simulation verification of multi-loop pi control system for grid connected medium power current source inverter}

To further validate the performance of grid connected current source inverter based photovoltaic system, simulation results for the exchange of medium active and reactive power and output waveshapes are presented in this section. Table 1 lists the parameters used for the grid connected CSI.

Reference active current, $I_{\text {dref }}$ is set to $50 \mathrm{~A}$ while reactive current reference, $I_{\text {qref }}$ is $0 \mathrm{~A}$ to achieve unity power factor. Figure $4(a)$ shows that $I_{d}$ and $I_{q}$ able to track their references when the CSI is operated at rated power. Figure $4(b)$ shows the performance of capacitor voltage used in the inner control loop regulator. The inverter operates at full medium active power $(120 \mathrm{~kW})$ as in Figure 4(c) with the exchange at $415 V_{a c}$ grid voltage, shown in Figure $4(d)$. Output current is shown in Figure 4(e) while Figure 4(f) shows that the normalized grid voltage is in phase with the current in this unity power factor application. Figure $4(g)$ presents the modulation index achieved almost 0.8 when the output current is at $50 \mathrm{~A}$.

For performance demonstration of the grid-connected CSI under varying weather conditions, the test system shown in Figure 3 is simulated with the following parameters: the PV array is modelled as a 
current source that varies its current injection $\left(i_{p v}\right)$ with weather, and in this case $i_{p v}$ is varied from $50 \mathrm{~A}$ to $60 \mathrm{~A}$; dc-link inductor $=40 \mathrm{mH}$; converter rated apparent power=100kVA; rated ac grid line voltage $=380 \mathrm{~V}$; switching frequency $=2.1 \mathrm{kHz}$; and an LC-filter with $3 \mathrm{mH}$ and $80 \mu \mathrm{F}$ inductance and capacitance respectively.

The simulation results of the CSI under varying weather conditions are shown in Figure 5. As PV array output current varies from $50 \mathrm{~A}$ to $60 \mathrm{~A}$ at 0 to $4 \mathrm{sec}$, dc-link current varies accordingly as shown in Figure 5(a). The output current is changed from 50A to $60 \mathrm{~A}$ at $2 \mathrm{sec}$ in order to see the response of the proposed control method in term of its dynamic when the new reference is introduced. When a new dc-link reference voltage is tracked by the MPPT, and using a typical proportional-integral dc-link voltage regulator, the measured dc-link voltage able to track the reference successfully and satisfactory. This is illustrated in Figure 5(b). The injected output currents are in phase with the voltage at the PCC (point of common coupling) as required by grid code and shown in Figure 5(c) and the active-reactive power exchanged with the ac network is shown in Figure $5(d)$. From these results, it can be inferred that PV grid integration using the CSI is satisfactory and can relatively be an alternative option to other grid integration unit. CSI offer features of simple ac-filter design and direct control of injected ac output current.

Although this work shows promising results using CSI as the integration unit, it is however bound by simulation results and the parameter is limited by the specified values as listed in Table 1. Different range of parameter may produce different ranges of voltage, current and power yet the wave shape or waveform trend should be almost the same. Therefore, this work may serve as a guidance to the other researchers and academician who are currently working in grid connected converter application.

Table1 Parameters used in simulation for grid connected CSI

\begin{tabular}{|c|c|c|c|}
\hline Operating specification & & Values & Units \\
\hline Current at dc link & $I_{d c}$ & $50-60$ & A \\
\hline Switching frequency & $f_{s}$ & 2.1 & $\mathrm{kHz}$ \\
\hline Two-level converter rating & $S$ & 150 & $\mathrm{kVA}$ \\
\hline Active power & $P$ & 120 & $\mathrm{~kW}$ \\
\hline Reactive power & $Q$ & 90 & $\mathrm{kVAr}$ \\
\hline AC grid voltage (line-to-line) & $V_{a c}$ & 415 & $\mathrm{~V}$ \\
\hline Capacitor at ac filter & $C_{F}$ & 100 & $\mu \mathrm{F}$ \\
\hline Inductor at ac filter & $L_{F}$ & 3.0 & $\mathrm{mH}$ \\
\hline Turn ratio of the transformer & $N$ & $1: 1$ & \\
\hline Proportional gain of output current controller & $k_{P I}$ & 25 & $\Omega$ \\
\hline Integral gain of output current controller & $k_{I I}$ & 3200 & $\Omega \mathrm{s}^{-1}$ \\
\hline Proportional gain of capacitor voltage controller & $k_{P 2}$ & 1 & $\Omega^{-1}$ \\
\hline Integral gain of capacitor voltage controller & $k_{I 2}$ & 80 & $\Omega^{-1} \mathrm{~s}^{-1}$ \\
\hline
\end{tabular}

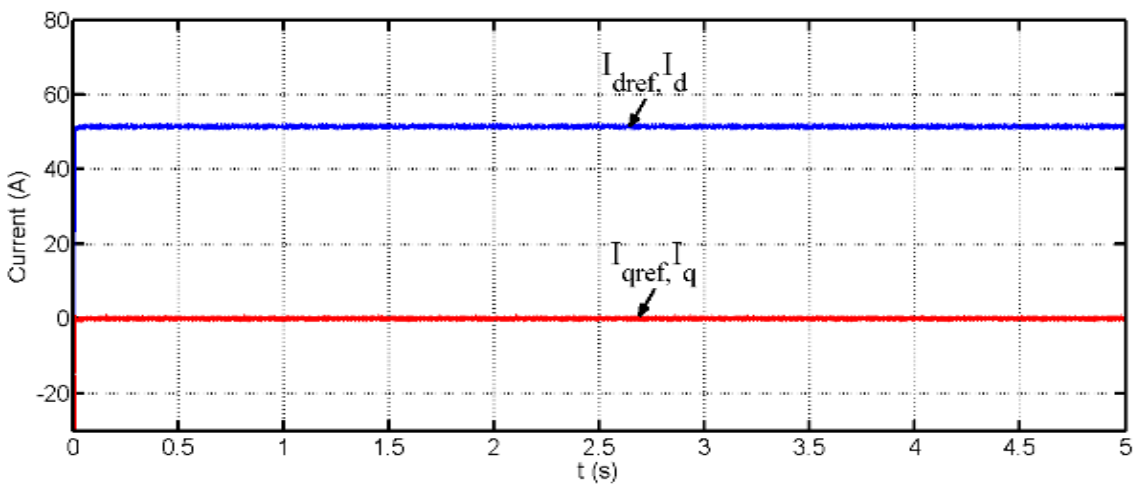

(a) $d q$ output current with their references 
S.A.Azmi et al.

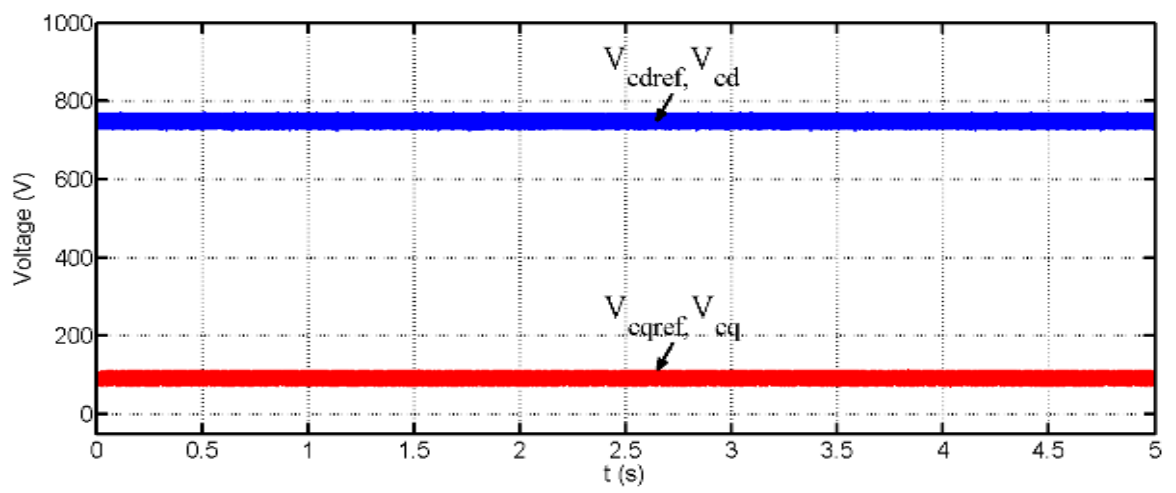

(b) Filtered capacitor voltage track their references in dq-term

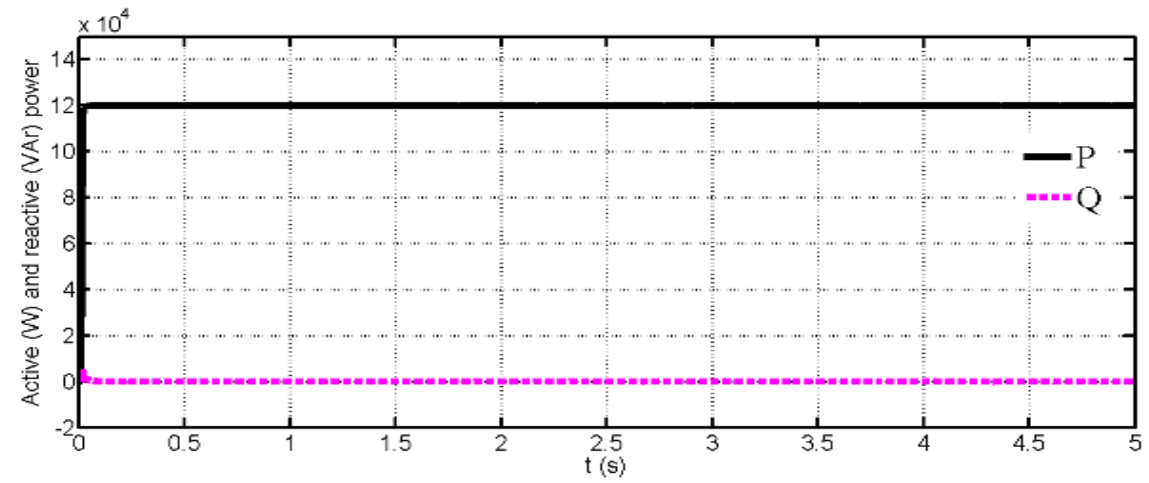

(c) Reactive-active power exchange with the ac network

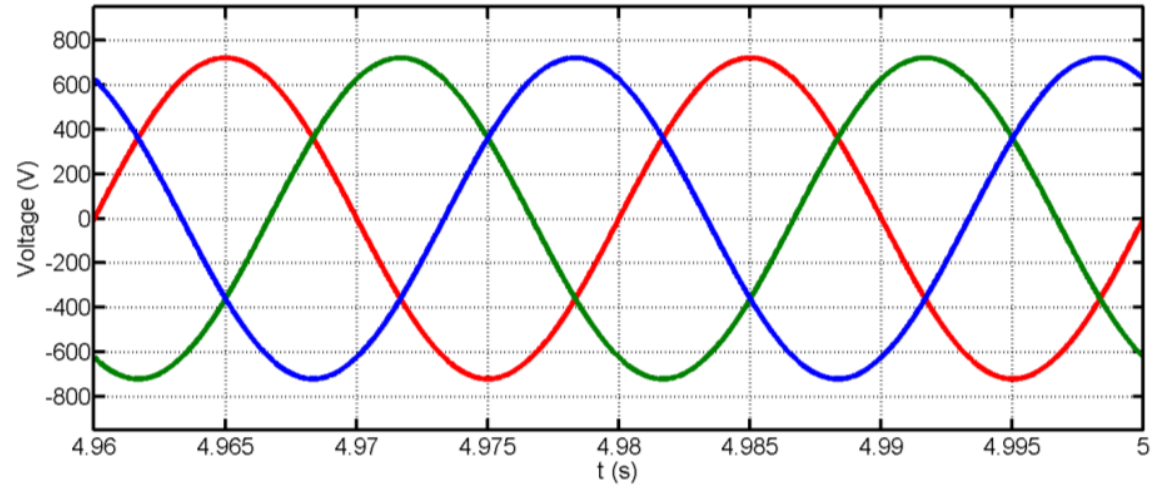

(d) Three-phase ac grid / utility voltage

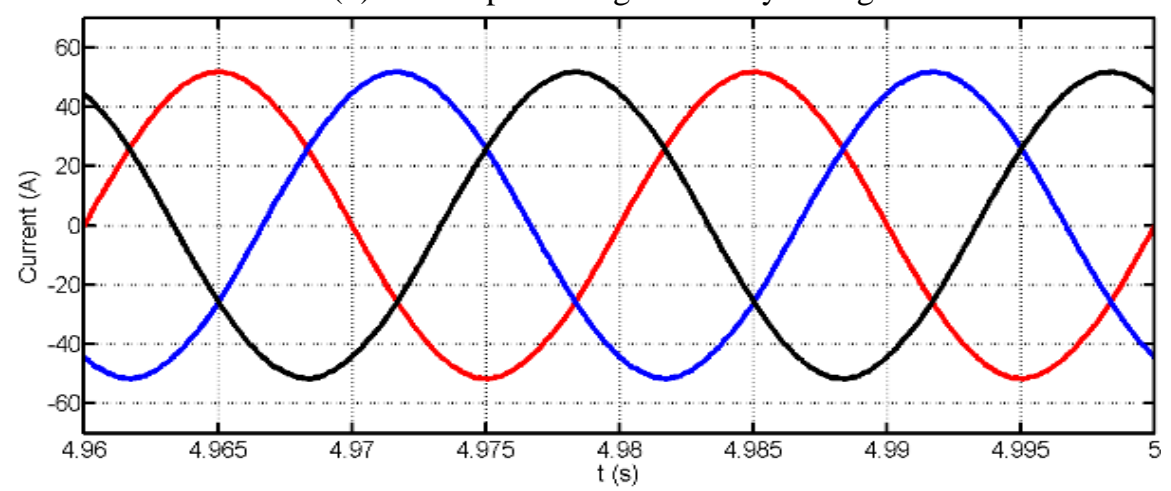

(e) Three-phase current at the output 


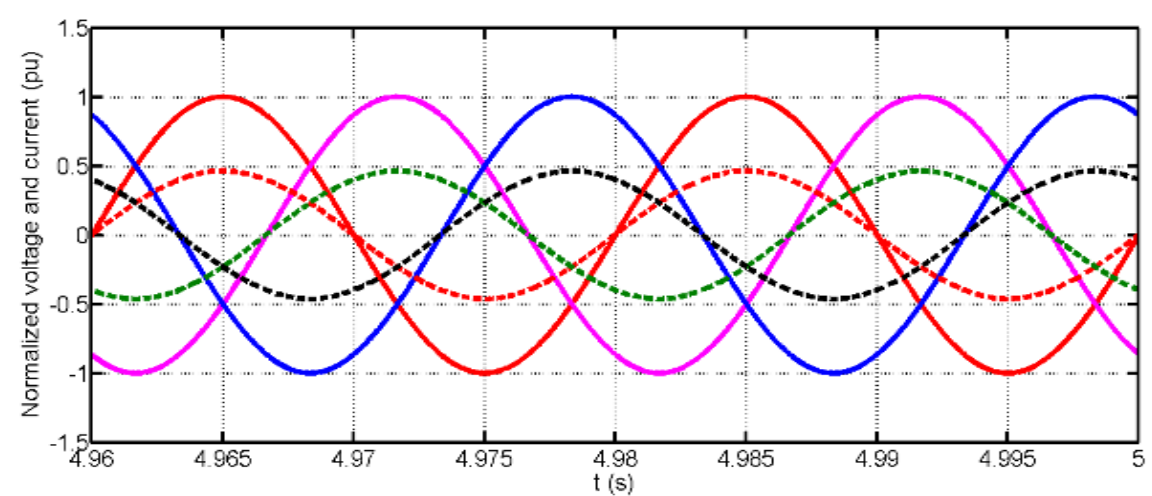

(f) In-phase normalized voltage and current

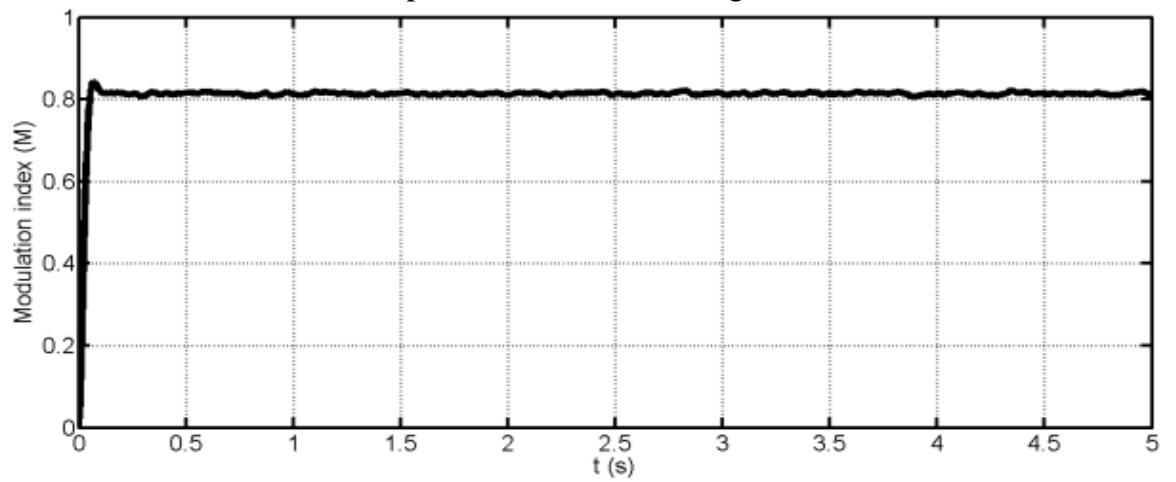

(g) Amplitude modulation index

Figure 4 CSI simulation results operating with the proposed DRSPWM with unity power factor

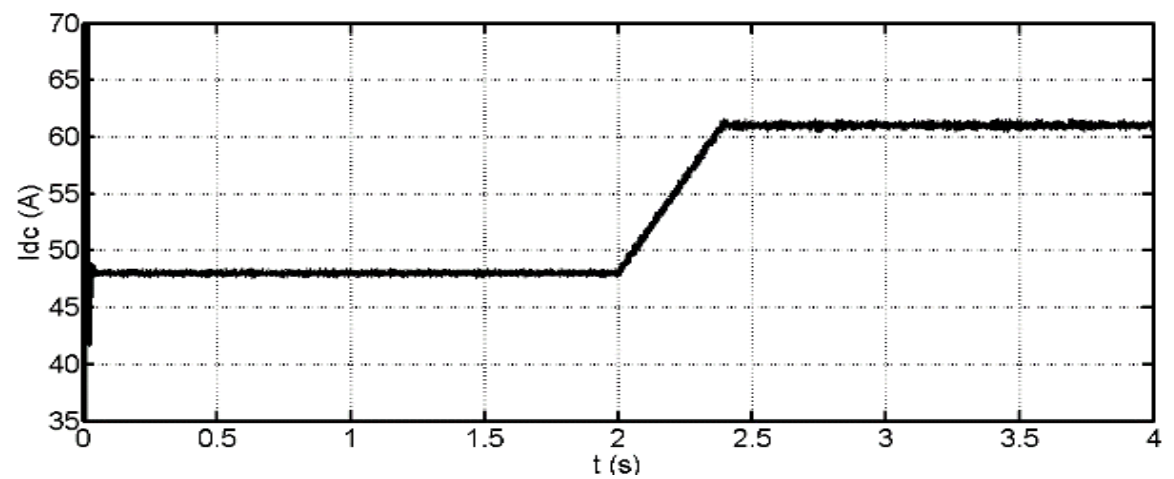

(a)Dc-link current

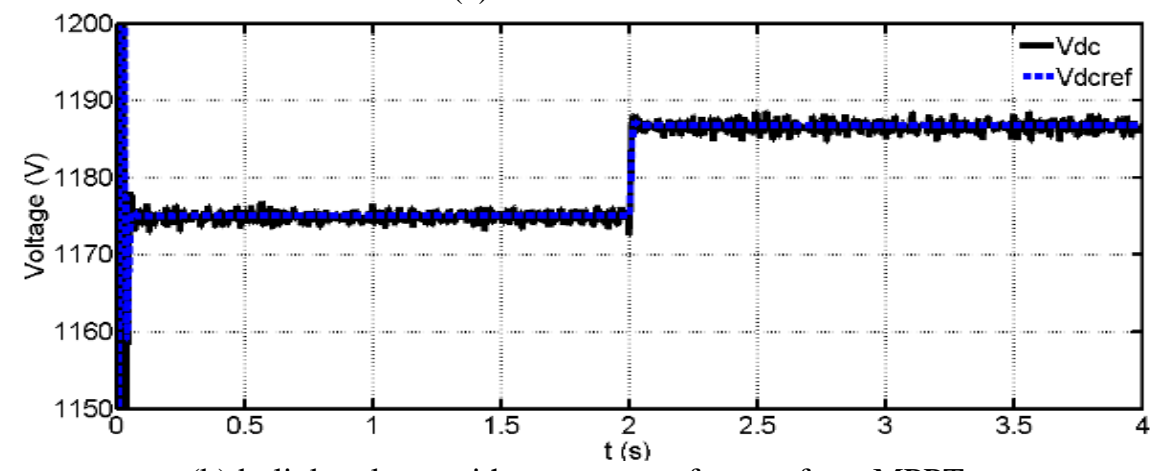

(b)dc-link voltage with respect to reference from MPPT 


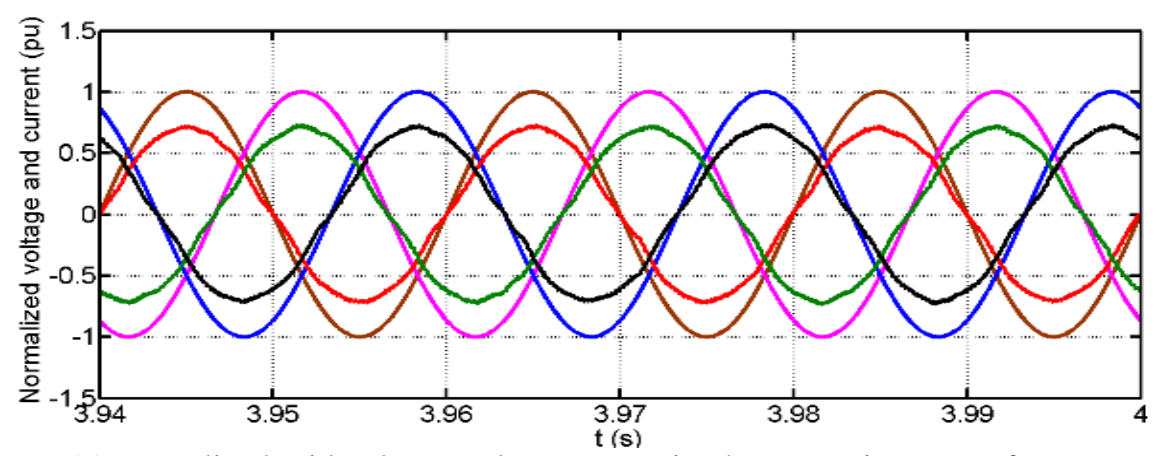

(c)Normalized grid voltage and current are in phase at unity power factor

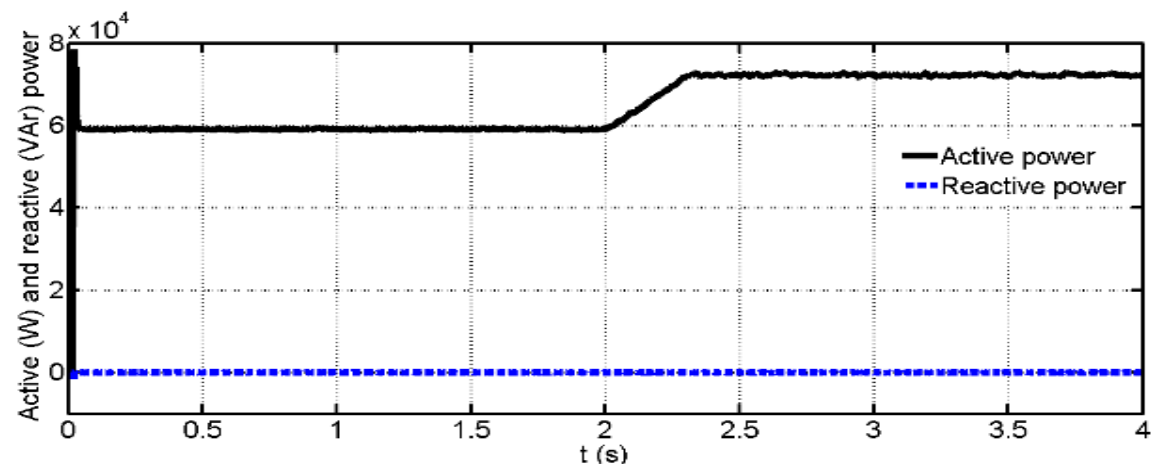

(d)Grid active and reactive power

Figure 5 Simulation results of CSI-PV system behaviour with variation in operational parameter

\section{Conclusion and future work}

The proposed multi-loop control system for a threephase current source inverter (CSI) in medium power photovoltaic system mainly consists of three subsystem which are dc-link voltage control for maximum power point tracking from PV panel and output current control for power flow exchanges between source and grid. The capacitor voltage control is added only to improve the controller bandwidth, not as part of current control and power flow to the grid. The performance of grid connected CSI system was analyzed using MATLAB/Simulink software. Results showed that the ac output current able to track its references at grid voltage of $415 \mathrm{~V}$ and active power of $120 \mathrm{~kW}$ in grid mode. With varying input from PV array, the dc-link control loop able to track the respective MPPT references which led to excellent tracking of output current with respect to the grid voltage. To conclude, the aim of this work which is to investigate the possibility of using CSI as an alternative for voltage source inverter (VSI) for grid interfacing unit is achieved based on the discussed results and analysis.

PV grid integration using CSI is proved to be satisfactory as a competitive option to common PV grid integration using VSI by providing simple acfilter design and direct current control of the injected output ac current. This work can be further verified by constructing a scaled-down prototype in laboratory and may consider other control system such as proportional-resonant control which more robust in present of imbalance phase voltage or fault.

\section{Acknowledgment}

The authors would like to acknowledge Faculty of Electrical Engineering Technology, Universiti Malaysia Perlis for the continuous support and encouragement of this research. This research is supported by Ministry of Higher Education Malaysia under the Fundamental Research Grant Scheme (FRGS), project code: FRGS/1/2019/TK07/ UNIMAP/02/9.

\section{Conflicts of interest}

The authors have no conflicts of interest to declare.

\section{References}

[1] Dai J, Xu D, Wu B. A novel control scheme for current-source-converter-based PMSG wind energy conversion systems. IEEE Transactions on Power Electronics. 2009; 24(4):963-72.

[2] Dash PP, Kazerani M. A multilevel current-source inverter based grid-connected photovoltaic system. In 
north american power symposium 2011 (pp. 1-6). IEEE.

[3] Wei Q, Xing L, Xu D, Wu B, Zargari NR. Modulation schemes for medium-voltage PWM current source converter-based drives: an overview. IEEE Journal of Emerging and Selected Topics in Power Electronics. 2018; 7(2):1152-61.

[4] Wu B, Pontt J, Rodríguez J, Bernet S, Kouro S. Current-source converter and cycloconverter topologies for industrial medium-voltage drives. IEEE Transactions on Industrial Electronics. 2008; 55(7):2786-97.

[5] Rajeev M, Agarwal V. Single phase current source inverter with multiloop control for transformerless grid-PV interface. IEEE Transactions on Industry Applications. 2018; 54(3):2416-24.

[6] Tahmasbi Fard M, Tarafdar Hagh M. Current source inverter based grid connected hybrid pv-wind power generation unit. International Journal of Electronics. 2020; 107(5):839-57.

[7] Azmi SA, Adam GP, Rahim SA. Voltage-controlled of a three-phase current source inverter in islanded operation. Indonesian Journal of Electrical Engineering and Computer Science. 2019; 16(1):15664.

[8] Azmi SA, Adam GP, Williams B. New direct regularsampled pulse-width modulation applicable for grid and islanding operation of current source inverters. IET Power Electronics. 2014; 7(1):220-36.

[9] Nisha KC. A transformer-less current source inverter for grid-connected SPV system. In international WIE conference on electrical and computer engineering 2019 (pp. 1-5). IEEE.

[10] Patel H, Agarwal V. A single-stage single-phase transformer-less doubly grounded grid-connected PV interface. IEEE Transactions on Energy Conversion. 2009; 24(1):93-101.

[11] Dash PP, Kazerani M. Dynamic modeling and performance analysis of a grid-connected currentsource inverter-based photovoltaic system. IEEE Transactions on Sustainable Energy. 2011; 2(4):44350.

[12] Alajmi BN, Ahmed KH, Adam GP, Williams BW. Single-phase single-stage transformer less gridconnected PV system. IEEE Transactions on Power Electronics. 2012; 28(6):2664-76.

[13] Sahan B, Vergara AN, Henze N, Engler A, Zacharias P. A single-stage PV module integrated converter based on a low-power current-source inverter. IEEE Transactions on Industrial Electronics. 2008; 55(7):2602-9.

[14] Ouchi T, Fujikawa H, Masukawa S, Iida S. A control scheme for a three-phase current source inverter in utility interactive photovoltaic system. Electrical Engineering in Japan. 2001; 135(1):43-55.

[15] Guo X, Wang N, Zhang J, Wang B, Nguyen MK. A novel transformerless current source inverter for leakage current reduction. IEEE Access. 2019; 7:50681-90.
[16] Singh A, Mirafzal B. An efficient grid-connected three-phase single-stage boost current source inverter. IEEE Power and Energy Technology Systems Journal. 2019; 6(3):142-51.

[17] Migliazza G, Buticchi G, Carfagna E, Lorenzani E, Madonna V, Giangrande P, et al. DC current control for a single-stage current source inverter in motor drive application. IEEE Transactions on Power Electronics. 2020; 36(3):3367-76.

[18] Xing L, Wei Q. Series-connected current-source inverters: $\mathrm{f} \mathrm{SW}=60 \mathrm{~Hz}$. IEEE Transactions on Power Electronics. 2020; 35(9):8882-5.

[19] Xing L, Wei Q. Series-connected current source inverters with less switches. IEEE Transactions on Power Electronics. 2019; 35(6):5553-6.

[20] Azmi SA, Tajuddin MF, Mohamed MF, Hwai LJ. Multi-loop control strategies of three-phase two-level current source inverter for grid interfacing photovoltaic system. In conference on energy conversion (CENCON) 2017 (pp. 277-82). IEEE.

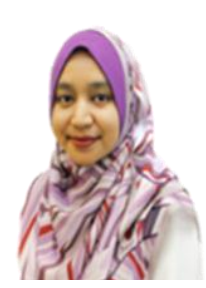

Syahrul Ashikin Azmi received a Bachelor degree in Electrcial and Electronic Engineering from Universiti Teknologi Petronas in 2004, MSc in Electrical Power Engineering from UNSW Australia in 2005 and PhD in Electrical Engineering from University of Strathclyde, UK in 2014. She is currently working as Senior Lecturer in Universiti Malaysia Perlis. Her research interests include Power Converter Topologies, Modulation Techniques and Control, Renewable Energy Generation Particularly Photovoltaic System

Email: ashikin@unimap.edu.my

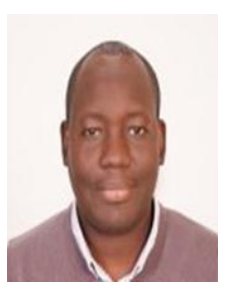

Grain P. Adam (M'10) received the first class B.Sc. and M.Sc. degrees from the Sudan University for Science and Technology, Khartoum, Sudan, in 1998 and 2002, respectively, and the $\mathrm{Ph} . \mathrm{D}$. degree in power electronics from the University of Strathclyde, Glasgow, U.K., in 2007. He has been working as a Research Fellow with the Institute of Energy and Environment, University of Strathclyde since 2008. His research interests include fault-tolerant voltage source converters for HVDC systems, control of HVDC transmission systems and multiterminal HVDC networks, voltage source converter-based FACTS devices, and grid integration issues of renewable energies. He has authored and coauthored several technical reports, and journal and conference papers in the area of multilevel converters and HVDC systems, and grid integration of renewable power. Also, he is actively contributing to reviewing process for several IEEE and IET Transactions and Journals, and conferences. Dr. Adam is an active Member of the IEEE Power Electronics Society. 


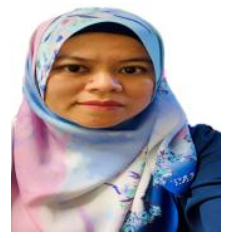

Siti Rafidah Abdul Rahim received the Diploma in Electrical Engineering (Power) from Universiti Teknologi Malaysia in 1999, Bachelor of Electrical Engineering (Hons) and MSc in Electrical Engineering from Universiti Teknologi MARA in 2003 and 2006 respectively. She is currently senior lecturer at Faculty of Electrical Engineering Technology, Universiti Malaysia Perlis. Her research interest includes Artificial Intelligence Application in Power System and Distributed Generation (DG).

Email: rafidah@unimap.edu.my

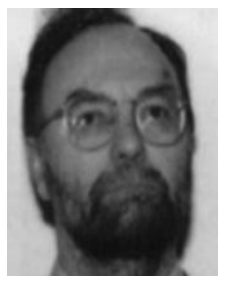

Barry W. Williams received the M.Eng.Sc. degree from the University of Adelaide, Adelaide, Australia, in 1978, and the Ph.D. degree from Cambridge University, Cambridge, U.K., in 1980. After seven years as a Lecturer with Imperial College, University of London, U.K., he was appointed as a Chair of Electrical Engineering, Heriot-Watt University, Edinburgh, U.K, in 1986. He is currently a Professor at Strathclyde University. His teaching covers power electronics (in which he has a free internet text) and drive systems. His research interests include power Semiconductor Modelling and Protection, Converter Topologies, Soft-Switching Techniques, and Application of ASICs and Microprocessors to Industrial Electronics. 